\title{
ESCOLA PÚBLICA E LIBERALISMO NO BRASIL IMPERIAL: CONSTRUÇÃO DO ESTADO E ABANDONO DA NAÇÃO
}

DOI: http://dx.doi.org/10.1590/2236-3459/57191

\author{
Dalvit Greiner de Paula \\ Universidade do Estado de Minas Gerais (UEMG), Brasil \\ Vera Lúcia Nogueira \\ Universidade do Estado de Minas Gerais (UEMG), Brasil
}

\section{$\cos 8$}

\begin{abstract}
Resumo
O presente artigo discute o direito à educação de nosso primeiro legislador constitucional em 1824 que confere à Constituição do Império um caráter liberal. Assim, analisamos nossa primeira Constituição atentando para aqueles artigos e parágrafos que professam os direitos do cidadão identificando os direitos sociais, principalmente o direito à educação. Nessa análise, buscamos compreender como o liberalismo se apresenta no Brasil tentando incluir o país num sistema capitalista mundial negando o que havia de mais essencial do sistema, restringindo a competição ao criar dois patamares de cidadania, garantindo às elites todos os seus direitos e negando aos demais aqueles direitos mais essenciais para a consolidação do povo e da nação. Dessa forma, o legislador priorizou a formação e consolidação do Estado por intermédio de suas instituições deixando de lado a nação que o constituiria negando-lhe um dos seus principais direitos: a educação.

Palavras-chave: liberalismo, educação, Constituição de 1824.
\end{abstract}

\section{PUBLIC SCHOOL AND LIBERALISM IN BRAZILIAN EMPIRE: EMERGENCE OF THE STATE AND NATION OF ABANDONMENT}

\begin{abstract}
This article examines the right to education of our first constitutional legislator in 1824 that gives Brazilian Empire Constitution a liberal feature. Thus we analyze our first Constitution paying attention to those articles and paragraphs professing Citizenship Rights identifying social rights, especially the right to education. In this analysis we seek to understand how liberalism is presented in Brazil trying to include the country into a world capitalist system denying what was the most essential system restricting competition to create two levels of citizenship, preserving the elites and all their rights and denying others to more essential rights for the consolidation of the people and the nation. Thus, the legislator gave priority to the formation and consolidation of the state through its institutions leting aside the nation that would be denying one of its main rights: The Education.

Keywords: liberalism, education, 1824 Brazilian Empire Constitution.
\end{abstract}




\section{ESCUELA PÚBLICA Y EL LIBERALISMO EN BRASIL IMPERIAL: CONSTRUCCIÓN DEL ESTADO Y ABANDONO DE LA NACIÓN}

\section{Resumen}

Este artículo aborda el derecho a la educación de la primera ley constitucional de Brasil en 1824 que le da la Constitución del Imperio un carácter liberal. Por lo tanto, analizamos nuestra primera constitución dedicando atención a esos artículos y párrafos que profesan Derechos de Ciudadanía identificando los derechos sociales, en especial el derecho a la educación. En este análisis se busca entender cómo se presenta el liberalismo en Brasil tratando de incluir al país en un sistema capitalista mundial negando lo que era más esencial del sistema mediante la restricción de la competencia para crear dos niveles de la ciudadanía, la preservación de las élites de todos sus derechos y niega otros esos derechos más esenciales para la consolidación de la gente y la nación. Por lo tanto, el legislador dio prioridad a la formación y consolidación del Estado a través de sus instituciones dejando de lado la nación que se niega uno de sus principales derechos: la educación.

Palabras clave: el liberalismo, educación, Constitución Brasileña de 1824.

\section{ÉCOLE PUBLIQUE ET LIBÉRALISME AU BRÉSIL IMPERIAL: CONSTRUCTION DE L'ETAT ET L'ABANDON DE LA NATION}

\section{Résumé:}

Cet article traite du droit à l'éducation des premières lois constitutionnelles du Brésil en 1824 qui donne la Constitution de l'Empire un caractère libéral. Ainsi, nous analysons notre première Constitution de prêter attention à ces articles et paragraphes professant droits à la citoyenneté identification des droits sociaux, en particulier le droit à l'éducation. Dans cette analyse, nous cherchons à comprendre comment le libéralisme est présenté au Brésil essayant d'inclure le pays dans un système capitaliste mondial nier ce qui était le plus essentiel du système en limitant la concurrence pour créer deux niveaux de citoyenneté, en préservant les élites de tous leurs droits et nie autre ces droits les plus essentiels pour la consolidation du peuple et de la nation. Ainsi, le législateur a donné la priorité à la formation et à la consolidation de l'Etat à travers ses institutions abandonner la nation qui serait nier l'un de ses principaux droits: l'éducation.

Mots-clés: libéralisme, education, Brésilien Constitution 1824. 


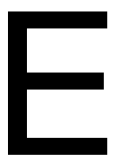

ste artigo pretende mostrar como no início do século XIX, no Brasil, o Liberalismo, adaptado à nossa cultura patriarcal e escravocrata, teve como principal preocupação a defesa e garantia do Estado como patrimônio do rei e não com a fundação de uma nação que tivesse neste mesmo Estado a sua máxima personificação perante os outros povos. Entendendo a cultura como anterior à escola e que as leis positivam os hábitos e costumes de um povo, a nossa pretensão é observar como a Constituição Imperial de 1824, feita sem representação popular, garantenos em seu nascedouro uma educação no seu formato liberal, apenas com o seu aspecto econômico, deixando de lado as possibilidades de uma educação emancipatória proposta pelos filósofos liberais europeus, de onde se busca inspiração.

Porém, cabe uma advertência: "a importância da lei não pode ser identificada e reconhecida como um instrumento linear ou mecânico de realização de direitos sociais. Ela acompanha o desenvolvimento contextualizado da cidadania em todos os países" (CURY, 2014, p. 15). Por isso e, portanto, o olhar que se tem aqui não desconhece as lutas e as ações de populares e de muitos intelectuais pela educação no Brasil, mas pretende analisar tão-somente como nosso primeiro arcabouço legal permitiu apenas a consolidação da espera e não da mudança.

O artigo se divide em duas partes e uma conclusão: na primeira parte uma rápida exposição da influência liberal na construção de nossa primeira Constituição no tocante ao direito à educação, que é o tema deste estudo; na segunda parte uma análise da tentativa de correção de rumo do direito à educação por meio da Lei Leôncio de Carvalho. Partimos do princípio de que continuamos esperando a formação da nação através de um direito universal, mas não universalizado, entendendo a educação como direito e não como uma necessidade, sendo a mesma o principal motor da justiça social num país.

Para entendermos a influência liberal na nossa primeira Constituição política inspiramo-nos nas mudanças que presenciamos neste início de século $\mathrm{XXI}$, das transformações pelas quais passa o mundo do trabalho que nos põe a pensar qual o lugar da educação nos dias de hoje. E, por conseguinte, qual o lugar do professor. O Brasil chega à globalização sem ter experimentado plenamente a modernização e isso nos traz problemas quanto ao entendimento do lugar da educação e de nosso fazer profissional. Assim, para entendermos a consolidação da realidade, tanto o profissional de educação quanto o trabalhador manual, em qualquer tempo e lugar, é preciso compreender que

[...] a força de trabalho, além de ser um dos elementos constitutivos da relação social que a aprisiona e "submete", é também um elemento que nega aquela relação e por isso mesmo sua "subordinação" precisa ser reiteradamente afirmada. É nesse processo que o capital visa a superar uma subordinação (melhor: subsunção) meramente formal, transformando-a em real (subsunção real), com o corolário de que a transformação da força de trabalho em capital acaba por consolidar-se socialmente. (ANTUNES; ALVES, 2004, p. 344).

Experimentamos, ao longo do século XX, nossa lenta saída de uma sociedade agrária e vimos passando por surtos de industrialização e urbanização que requerem um novo tipo de Estado e um novo tipo de trabalhador. Ao contrário das revoluções americana e francesa nossa elite econômica não promoveu uma revolução política para chegar ao poder, mas foi construindo, por outras vias, um capitalismo tão excludente e seletivo quanto o americano ou o europeu. Por outro lado, precisou promover reformas - 
de todos os níveis e tipos - para a manutenção da ordem social e do poder político. Para essas reformas serviu-se muito bem da educação ao longo dos últimos duzentos anos. Ora ofertando e ampliando para civilizar, ora negando e restringindo para controlar, portanto sempre limitando. E esse controle aparece mais inicialmente com a formação do Estado brasileiro em 1822.

Nossa primeira Constituição, apelidada a Constituição da Mandioca, outorgada em 1824 pelo imperador D. Pedro I, segue a linha do constitucionalismo britânico onde o que interessa é a defesa do Estado e do Rei e daqueles direitos do cidadão somente naquilo que o Estado se obriga a garantir, a cidadania, mas não a promovê-la. $A$ Constituição de 1824 é claramente dividida em duas partes onde a primeira parte trata do Estado e do Rei enquanto encarnação da autoridade estatal e a segunda parte trata dos direitos do cidadão. Mas, a principal característica é aquela de que tudo aquilo que se encontra no campo do privado não é objeto de ingerência do Estado, então não objeto constitucional, exceto, no caso do Brasil, a religião tomada como religião do Estado. Ou seja, não há uma tentativa de promover o cidadão como constituinte da Nação e do Estado e a cidadania como principal característica de uma Democracia. Declara-se abertamente no

Art. 178 - É só constitucional o que diz respeito aos limites e atribuições respectivas dos poderes políticos, e aos direitos políticos e individuais dos cidadãos; tudo o que não é constitucional pode ser alterado, sem as formalidades referidas, pelas legislaturas ordinárias. (BRASIL, 1824).

Dessa forma, criamos uma Constituição em que os direitos políticos têm sua garantia constitucional - e daqui deriva o cidadão e a liberdade, não de todos, é claro! - e relegamos às legislaturas ordinárias qualquer outra espécie de direito, principalmente os direitos sociais de onde se constituiria a cidadania e a igualdade. Exemplo bastante é a Lei Áurea: simples lei ordinária, e não uma emenda constitucional, que não depende das "formalidades referidas" contidas na mesma Constituição, para perder seu valor de lei. Assim cria-se uma Constituição que se pauta pela imutabilidade no tempo impedindo que as lutas, sejam quais forem, não inscrevam seus resultados na lei maior como uma ampliação de direitos fundamentais do cidadão. Ao criar os contornos daquilo que consideramos direitos políticos, nossa primeira Constituição reflete na lei a sociedade elitista que a compôs criando uma democracia censitária, sequer refletindo os conflitos da elite que a gerou, na medida em que foi concertada, outorgada e não debatida e votada. Daí o seu codinome Constituição da Mandioca, raiz e fonte de poder dos ricos e referência ao alimento ofertado aos escravos e daqueles que tinham terra suficiente para plantá-la e alimentar seu plantel.

Dentre os limites e atribuições do poder político, a ideia do Poder Moderador nas mãos da pessoa inviolável e sagrada do Imperador não é uma novidade em termos ideais, mas o é em termos práticos na medida em que Brasil e Portugal foram dos poucos países que usaram dessa estratégia. Concordando com Bobbio (2000), nossa primeira Constituição é

[...] uma típica forma de ficção jurídica, que tem por objetivo salvaguardar o princípio da superioridade do rei, e portanto assegurar a permanência da forma de governo monárquica, não obstante a ocorrida limitação dos poderes tradicionais do detentor do poder supremo. (BOBBIO, 2000, p. 14). 
Tal estratégia que pretendia colocar o rei acima das paixões partidárias faz de D. Pedro I um rei muito próximo do absolutismo "para que incessantemente vele sobre a manutenção da Independência, equilíbrio, e harmonia dos mais Poderes Políticos" (BRASIL, 1824). Dessa maneira, a Constituição limita e delimita a participação no exercício do poder atribuindo apenas àqueles da elite próxima do rei a interlocução com o Estado - aqueles que "a Constituição de 1824 os havia identificado como cidadãos ativos. Eles próprios se reconheciam como membros da boa sociedade" (MATTOS; GONÇALVES, 1994, p. 8, grifo dos autores) -, excluindo os demais populares de qualquer interlocução direta ou mesmo mediada por partidos políticos, inexistentes à época, porém, comuns e necessários numa democracia, seja ou não, liberal. Assim, a Constituição que pretendia dar a um Estado Monárquico Constitucional o cunho liberal surge como um arremedo de democracia, pois negou exatamente aquilo que prega o pensamento liberal clássico, no dizer de Bobbio (2004), em que a igualdade diante da lei é a recusa de uma sociedade estamentária e os sujeitos originários são apenas indivíduos iguais em todos os direitos fundamentais elencados na Constituição. Essa mesma Constituição mantém o caráter estamentário de nossa sociedade criando dois níveis de cidadãos - com e sem renda, os de primeira e os de segunda classe - e dois tipos de brasileiros - com e sem liberdade. Portanto,

À época da Independência, por exclusão socioétnica, 40\% dos habitantes não tinham acesso à educação como também não eram considerados cidadãos. Se a isso ajuntarmos as mulheres, que, pela concepção organicista da época, se limitavam a uma cidadania passiva, então o universo dos não cidadãos ou cidadãos imperfeitos sobe consideravelmente (CURY, 2014, p. 25).

A marca dessa Carta constitucional é uma democracia censitária constituindo uma Assembleia Nacional composta apenas pela elite agrário-exportadora mantida pelo trabalho escravo, seguida de um Poder Moderador impedindo que as leis mais necessárias à construção da nação, entendendo aqui como um permanente alargamento dos direitos fundamentais, tornando-se por 65 anos um impedimento ao diálogo com 0 povo brasileiro colocando-o num estado de espera. Ou seja, enquanto

[...] predominaram atividades econômicas primário-exportadoras, durante os primeiro quatro séculos de sua existência (XVI a XIX), o exercício do trabalho esteve submetido à intensa desvalorização, identificada pela imposição do trabalho forçoso e do genocídio indígena, pela escravidão e barbárie de negros e ainda pelo sistema de colonato depreciativo a europeus e asiáticos migrantes. Nessa fase do país, a questão social não apareceu concretamente como um problema à nação, quando muito, como um caso de polícia às elites, a ser enfrentado pela repressão e autoritarismo das forças públicas e privadas. (POCHMANN, 2004, p. 7).

Dessa maneira, com repressão e autoritarismo, o legislador define as condições para a participação do grupo de cidadãos - e como consequência apresenta a sua definição de cidadão e de cidadania - fica marcada a condição de proprietário de bens e haveres suficiente para uma "decente subsistência" (BRASIL, 1824), além de ter nascido no Brasil "quer sejam ingenuos, ou libertos" (ibidem). Sendo uma Monarquia Constitucional com governo representativo a nossa democracia censitária previa que além das condições acima para as eleições paroquiais os valores de "duzentos mil réis" (ibidem) para candidatos ao Conselho de Província, "quatrocentos mil réis de renda 
liquida" (ibidem) para candidatos à Assembleia Nacional e "Oitocentos mil réis" (ibidem) para participar da lista tríplice para o Senado que deveria ser submetida ao Imperador pela província. Todos por eleição indireta numa fórmula que criava "uma massa dos cidadãos activos" (ibidem) separada daqueles outros cidadãos que "não tiverem de renda liquida annual cem mil réis por bens de raiz, industria, commercio, ou Empregos." (ibidem).

A imobilidade social patrocinada pela elite e inscrita na Constituição provoca a manutenção da pobreza durante o Império, o que demanda um enorme esforço, refletido no controle social, para que o país não cresça ou apenas o faça quando o surto de algum produto - o que hoje conhecemos como comoditties - tem seu valor alterado no mercado internacional, tais como ouro, café, borracha. Imediatamente volta a uma situação de baixo ou nenhum crescimento anual. Abreu e Lago (2001) esclarecem que:

\begin{abstract}
Utilizando dólares de 1990, [Maddison] estimou o PIB per capita brasileiro em 1820 em US\$ 646, contra US\$ 759 para o México e US\$ 1257 dólares para os EUA e a média de US\$ 1245 para doze países desenvolvidos da Europa Ocidental. Esses dados sugerem que o hiato entre o Brasil e os países mais avançados não teria sido ainda muito apreciável naquele ano. Já para 1890 , Maddison estimou para o Brasil um PIB per capita de US\$ 794 dólares, contra US\$ 2152 para a Argentina, e US\$ 1011 para o México, sendo as cifras correspondentes para o Reino Unido e os EUA respectivamente US\$ 4009 e US\$ 3392, o que indicaria crescimento bem mais lento do Brasil e aumento das disparidades em relação a outros países latino-americanos e a países desenvolvidos. (ABREU; LAGO, 2001, p. 5).
\end{abstract}

Numa comparação com valores de hoje, sem atualização monetária aqueles US\$ 646,00 em 1820 equivaleriam a $R \$ 2.007,00$ ligeiramente acima de dois salários-mínimos anuais de renda per capita. A população brasileira durante o Império, em média, estaria abaixo da linha de pobreza traçada por qualquer governo democrático atual e dos níveis aceitos pela Organização das Nações Unidas - ONU.

Os dados, por si só mostram o tamanho do fosso que a elite brasileira foi construindo para o país, especializando-se cada vez mais em produtos agrários com mão de obra escrava ao invés de investir em indústria e conhecimento. Isso aumentava rapidamente o nível de pobreza, porém a principal justificativa ideológica para uma não adesão ao clássico liberalismo econômico era a expectativa de vida de um operário inglês ser igual ou inferior ao de um escravo brasileiro. Assim, com baixo crescimento econômico e aumento significativo da população durante o período imperial "o PIB real per capita do Brasil teria aumentado apenas $22,9 \%$ entre 1820 e 1890, ou seja, a uma taxa anual ligeiramente inferior a 0,3\%" (ABREU; LAGO, 2001, p. 5). Na prática, isso significou total falta de investimentos no país e em direitos sociais deixando a assistência social como objeto de filantropia de famílias ricas de forma direta ou por intermédio da igreja.

Mesmo levando-se em consideração a falta de proteção social dos demais Estados comparados na informação acima, vê-se que os países latino-americanos que adotaram o liberalismo clássico, incluindo-se aí o trabalho livre e o fomento à educação, tiveram um crescimento médio superior ao do Brasil no mesmo período. Porém, seja por crescimento natural ou imigração, a população do país cresce de, aproximadamente, 4.000.000 para 14.000.000 de habitantes durante o Império e mesmo assim mantém seu 
alto índice de analfabetismo.

Essa falta de investimentos sociais, e como aqui tratamos de educação, vê-se que

Em 1821, um levantamento estatístico detalhado revelou população total de 112.695 habitantes na "Corte", ou seja, na cidade do Rio de Janeiro. Salvador possivelmente tinha cerca de 70 mil habitantes e Recife de 25 a 30 mil. De acordo com o censo de 1872 apenas três cidades tinham mais de 100 mil habitantes. O Rio continuava sendo o maior centro urbano com 275 mil habitantes. Salvador era ainda a segunda maior cidade, com 129 mil habitantes, seguida de Recife com 117 mil. A percentagem de analfabetos era de $\mathbf{8 4 , 3 \%}$ no Brasil como um todo. Em 1890, a cidade do Rio de Janeiro tinha 523 mil habitantes, Salvador, 174 mil, e Recife, 112 mil. São Paulo surgia como a quarta maior cidade do país com 65 mil habitantes. $O$ índice de analfabetismo do país como um todo permanecia em torno de $85 \%$. (ABREU; LAGO, 2001, p. 3, grifo nosso).

O Município da Corte quintuplicou sua população durante o Império. Nos últimos vinte anos do Império o analfabetismo teve um acréscimo percentual de $0,7 \%$ para uma população que dobrou no Rio de Janeiro e teve um aumento próximo de $50 \%$ em cidades como Salvador e Recife. Isso denota muito pouco ou nenhum investimento em educação.

O Império praticou o Estado Mínimo tão desejado pelos liberais. Uma sociedade que entende o cidadão apenas como aquele capaz de "decente subsistência" pressupõe a sua liberdade, de direito e de fato, para exercer os seus talentos à revelia do Estado. Conclui-se que esse Estado não deve se preocupar com o bem-estar material de seus cidadãos não devendo prover-Ihes nada que não seja a garantia da ordem para 0 exercício de seus contratos. Essa é a principal marca do pensamento liberal na construção do estado nacional brasileiro. A expressão "decente subsistência" é claramente demarcatória não no sentido de reconhecer o ponto de partida para a ação do Estado para promover a igualdade e a justiça social, como se verá ao longo do Império, mas de esclarecer quem têm direitos e a quê direito tem.

Assim, esclarece-se no

TITULO 8-- Das Disposições Geraes, e Garantias dos Direitos Civis, e Politicos dos Cidadãos Brazileiros.

[...]

Art. 179. A inviolabilidade dos Direitos Civis, e Politicos dos Cidadãos Brazileiros, que tem por base a liberdade, a segurança individual, e a propriedade, é garantida pela Constituição do Imperio, pela maneira seguinte.

$[\ldots]$

XXXI. A Constituição tambem garante os soccorros publicos.

XXXII. A Instrucção primaria, e gratuita a todos os Cidadãos.

XXXIII. Collegios, e Universidades, aonde serão ensinados os elementos das Sciencias, Bellas Letras, e Artes.

(BRASIL, CF, 1824).

Como se vê, "soccorros publicos" liga-se ao conceito de saúde e segurança individual e a "Instrucção primaria" liga-se ao conhecimento e à liberdade para obtê-la. A educação é vista como um exercício de liberdade individual devendo o Estado apenas inscrevê-la na Constituição e em lei ordinária. O financiamento é privado uma vez que ao Estado cabe apenas a vigilância da liberdade de buscá-la, não de provê-la. Ao considerarmos a linha de pobreza determinada pela Constituição como condição para alistamento eleitoral podemos inferir que a maior parte do financiamento à educação era 
uma relação entre entes privados. O hiato exposto nos itens XXXII e XXXIII do artigo 179 demonstra a relação de mercado proposta para um ensino propedêutico, preparatório para um curso superior, quando se abandona qualquer ação pública e popular de instrução. Educação e Saúde não estão inscritas na Constituição como um direito social e dever do Estado em provê-los. As parcas rubricas nas dotações orçamentárias do Império demonstram que a educação não era prioridade. A Lei de 15 de dezembro de 1830 que "orça a receita e fixa a despeza para o ano financeiro de 1831-1832" destina em seu Artigo $1^{\circ} \S 4^{\circ}$ a quantia de 8:302\$000 (oito contos, trezentos e dois mil-réis) para a instrução dos príncipes da Casa Imperial enquanto que para a Província do Rio de Janeiro é destinada 28:880\$000 (vinte e oito contos, oitocentos e oitenta mil-réis), ou seja 2,5 vezes para a província o valor destinado aos príncipes. Para um orçamento anual de $321: 175 \$ 780$ (trezentos e vinte e um contos, cento e setenta e cinco mil, setecentos e oitenta réis) a despesa com instrução pública significava apenas $9 \%$ do orçamento anual, ou seja, bem menos que os $25 \%$ garantidos pela nossa atual Constituição.

Quando surge a Lei das Escolas de Primeiras Letras em 15 de outubro de 1827 ela já vem marcada por um viés de racionalidade econômica que demonstra uma economia de recursos para a instalação e manutenção do que se chamou acima de instrução elementar e gratuita para todos. Sabemos dos efeitos da lei do Subsídio Literário e também sabemos o quanto ela não foi nem seria capaz de financiar uma educação pública mínima que fosse. Vejamos: a Constituição prevê "a todos os Cidadãos" enquanto que a Lei organiza a escola apenas naqueles lugares mais populosos, pois permite "extinguir as que existem em lugares pouco populosos" (BRASIL, 1827) além do mais o salário dos professores deve ser proporcional ao que pode pagar a localidade uma vez que é preciso "atenção às circunstâncias da população e carestia dos lugares". (BRASIL, 1827).

Quanto aos professores e professoras não há nenhuma preocupação em garantirIhes o mínimo necessário à sua formação em espaço público e gratuito como condição para o exercício de sua profissão, pois aqueles "que não tiverem a necessária instrução deste ensino, irão instruir-se em curto prazo e à custa dos seus ordenados" (BRASIL, 1827) para que possam continuar a sua atividade. Além do mais, como se vê acima, não temos no início do Império uma escola de formação de professores, pois seguindo a tradição do Período Joanino, a única preocupação foi com as escolas de ensino superior que formassem funcionários ligados à manutenção do Estado e não aos serviços que deveriam ser prestados por esse mesmo Estado.

A racionalidade econômica da Lei de 1827 impede que o exercício de um direito constitucional seja para todos os cidadãos. Ela contradiz a Constituição, mas não é inconstitucional. Assim, começamos a esperar.

Como vimos, o processo de inserção do Brasil na economia mundial dá-se no seu descobrimento na medida em que a empresa agrária produtora de açúcar demandou certa qualificação técnica necessária para a produção e o transporte do produto. Nessa fase nascente do capitalismo, de caráter mercantilista, não havia muito que fazer em termos de educação uma vez que aqui não havia necessidade de um modelo educacional que não fosse a mera repetição, por gerações e gerações, de fazeres autômatos, sem muita novidade técnica ou científica. Servíamos ao capitalismo no exterior praticando o escravismo e a matança de negros e índios. A reprodução do sistema e da sociedade era 
garantida com o envio dos filhos dos homens de bens à Europa e mantendo cativos e ignorantes os filhos da terra.

Quando se diz do surgimento do Brasil como fornecedor de insumos agrícolas no mercado capitalista internacional, inserção que se dá já no século XVI com o seu descobrimento econômico enquanto fornecedor de pau-brasil - ou pau de tinta - para as tecelagens europeias. Seguem os ciclos do açúcar e do ouro. Apesar de parte do sistema, isso não nos coloca sequer como um país próximo do capitalismo nos trezentos anos de colônia nem mesmo quando da independência e instituição do Estado em 1822. Giddens (1991) ajuda-nos a compreender esclarecendo que

O capitalismo é um sistema de produção de mercadorias, centrado sobre a relação entre a propriedade privada do capital e o trabalho assalariado sem posse de propriedade, esta relação formando o eixo principal de um sistema de classes. O empreendimento capitalista depende da produção para mercados competitivos, os preços sendo sinais para investidores, produtores e consumidores. (GIDDENS, 1991, p. 53).

Daí derivaria instituições modernas resultantes do individualismo burguês e de uma cultura capitalista. Instituições que são uma expressão das Luzes, no seu aspecto cultural e do Liberalismo, tanto no seu aspecto político quanto econômico. As duas primeiras instituições são anunciadas pelo autor: a propriedade privada e o trabalho assalariado. O Brasil do Oitocentos não tem nem uma nem outra, na medida em que uma pressupõe a outra. O Brasil não tem na terra a propriedade privada, entendida stricto sensu como a propriedade do único meio de produção que provê os homens de alimentos, de poupança como nos cercamentos ingleses e de capital produtivo como hoje, uma vez que toda a terra era propriedade do rei. A terra não era nem capital nem garantia, pois o seu possuidor não era o seu proprietário. Isso somente se dá em 1850 com a Lei 601 de 18 de setembro de 1850, a Lei de Terras, que encerra o regime dominial e institui a propriedade privada da terra no Brasil.

O Brasil não tem trabalho assalariado uma vez que a instituição do trabalho se dava pela escravidão do trabalhador, tratado como coisa, portanto sem direitos nem deveres, incapacitado de realizar contratos, quiçá o Contrato Social representado pela Constituição. Tratado como coisa não haveria a menor possibilidade de se pensar em classe, pois não existe uma classe social nestas condições abaixo da dignidade humana. O que o Brasil tem é uma jabuticaba1: o trabalhador é a propriedade.

A fundação do Estado brasileiro e suas instituições não se dão a partir dos antagonismos de uma classe contra a outra na medida em que não existem classes no Brasil do século XIX. O mercado, que pressupõe uma competição por produtos derivaria na competição política pelo Estado. Não presenciamos uma disputa pelo Estado de uma classe contra outra, pois é impossível falarmos de classe numa sociedade escravocrata.

\footnotetext{
1 Teoria da jabuticaba é tudo aquilo que só existe no Brasil, como essa saborosa fruta selvagem da respeitada família das mirtáceas (myrciaria jaboticaba). Isso significa, para ser rápido, pertencer a uma família de "explicações sociais" única e exclusiva neste planeta Terra, situação inédita no plano universal, que consiste em propor, defender e sustentar, contra qualquer outra evidência lógica em sentido contrário, soluções, propostas, medidas práticas, iniciativas teóricas ou mesmo teses (em alguns casos, até antíteses) que só existem no Brasil e que só aqui funcionam, como se o mundo tivesse mesmo de se curvar ante nossas soluções inovadoras para velhos problemas humanos e antigos dilemas sociais. (ALMEIDA, 2005, s/p).
} 
Aqui encontramos os primeiros problemas uma vez que no Brasil não se criou uma cultura de poupança e acumulação que permitisse a formação de um capital privado, portanto, não havia necessidade de leis e instituições que protegessem tal capital. A aplicação dos capitais gerados pela mão de obra escrava era investida no bem-estar dos ocupantes da casa-grande gerando uma cultura de opulência, acreditando-se na inesgotabilidade dos recursos na medida em que a natureza proporcionava a reposição do plantel de escravos com a reprodução biológica, seja com a relação amorosa entre iguais ou pelo estupro do mais forte.

Assim, sem propriedade privada nem trabalho assalariado, as instituições brasileiras não nascem sob o caráter liberal-capitalista vigentes na Europa do século XIX, pois, já constatava José Bonifácio de Andrada e Silva (1763-1838) "o governo deriva da propriedade e não vice e versa, é contra a natureza que o princípio dependa do seu derivado". (SILVA, 2000, p. 139).

Nossa cultura é outra e outras são as nossas instituições. Daí é outra a nossa educação. José Bonifácio propõe a importação de mentes e nada de novidades. Não se deve inventar modas educacionais. Apenas importar e com o tempo formar. Deve-se "não querer ser original, mas imitador por ora" (SILVA, 2000, p. 89). A questão que se põe para a História é imitar a quem. Assim, em carta a Domingos António de Sousa Coutinho (1760-1833), o conde de Funchal, Bonifácio anexa sua lista para o melhoramento do Brasil e em seu ordenamento a educação é o último item. Mesmo assim, fica evidente a sua crença de que só a educação melhora um povo e consequentemente, seu governo.

Quixote das ideias industrialistas brasileiras, Irineu Evangelista de Souza (18131889), o barão, depois visconde de Mauá, liberal formado na escola inglesa, não conseguia ver outra saída para o Império senão se render ao livre mercado modernizando as instituições a começar pela inserção legal e proteção do trabalho assalariado e a abolição da escravatura. E essa foi a sua luta durante toda a sua vida que, ironicamente, se confunde com a vida do imperador D. Pedro II. Ser liberal não era mais se manter conservador para manter a unidade nacional, porém mudar para modernizar-se e modernizar o país diante da economia capitalista e liberal da Europa e dos Estados Unidos. Isso significava mais escolas. Porém,

Os processos brasileiros vêm sendo fulcrados por características e propriedades específicas desde o transplante da corte portuguesa para o Rio de Janeiro em 1808, ou da febre das estradas e dos melhoramentos urbanos no Império ou, ainda, se associando à ideia de ciência como salvação, cultivada nas academias militares, na Escola Politécnica e nas faculdades de Medicina no século XIX, do esforço por instituir o progresso além dos limites do comercialismo exportador e importador, mas também desde a percepção de heranças múltiplas interpretadas, sistematicamente, como entraves para a modernização brasileira, e mesmo nos surtos de modernização industrializante sustentados em ideologias liberais e/ou neoliberais. (CARVALHO, 2012, p. 30).

É assim que, preocupados com a não-fragmentação e o ordenamento jurídico do Estado, os liberais produzem uma legislação educacional que nasce e não se move durante o Primeiro Império. É sabido das autorizações para a instrução pública em todo o Império, mas com parco financiamento público. Poucas linhas, porém, bastante significativas na Constituição, na Lei das Escolas de Primeiras Letras de 1827 e no Ato Adicional de 1834 são suficientes para se perceber o valor dado à educação popular na 
construção da nação. Nenhum valor, nenhuma importância. Apesar dos Projetos para o Brasil, de José Bonifácio, a ideia liberal de um ensino público, natimorto nos documentos legais acima, só será novamente lembrada em 1868 dentro de um grande e ousado projeto de reforma política, que se propõe a mudar radicalmente os princípios constitucionais até então vigentes. Assim

\begin{abstract}
O programa liberal de 1868 , redigido por Nabuco, lembra os liberais exaltados de 1831: ele prega a descentralização política e administrativa, defende a abolição do Poder Moderador e advoga um Senado eletivo e vitalício. Quer que a escolha dos Presidentes seja feita pelos eleitores de cada Província, antecipando a Federação, preconiza a liberdade do ensino e postula uma polícia eleita pelos cidadãos. Defende o fim da Guarda Nacional e dos alistamentos compulsórios, propõe o voto direto e a sujeição dos Magistrados apenas ao julgamento dos Tribunais superiores, tornando-os imunes à ação do Executivo. Vinte anos depois, quando a República tornou-se inevitável, todas as propostas liberais, com exceção talvez da Federação, que seria fatalmente concedida, não fora o golpe militar, estavam atendidas. Até mesmo a questão crucial da escravidão que os liberais, de início, tão timidamente enfrentaram. (NOGUEIRA, 2012, p. 53, grifo nosso).
\end{abstract}

Porém, se nada mudava na sociedade com sua cultura bacharelesca, nada devia mudar na política e nas leis votadas na Assembleia Nacional. Se o diploma era visto com a distinção necessária a um bom emprego público não havia motivos para inflacionar o mercado com a chegada de mais novos candidatos de outros grupos sociais aos mesmos cargos. A nossa cultura não nos permitia - ou não nos permite - transformar a escola numa promotora de justiça social.

Com a necessidade de corrigir os rumos do país - e contra a conservação - surge uma nova onda liberal. Porém, era fundamental seguir os conselhos do Bruxo do Cosme Velho, Machado de Assis, expostos na Teoria do Medalhão: "toda questão é não infringir as regras e obrigações capitais. Podes pertencer a qualquer partido, liberal ou conservador, republicano ou ultramontano, com a cláusula única de não ligar nenhuma ideia especial a esses vocábulos" (ASSIS, 2007, p. 88) confirmando assim a expressão de Holanda Cavalcanti (1797-1863), político pernambucano de que não havia "nada mais parecido com um saquarema do que um luzia no poder".

O melhor exemplo de conservação na legislação educacional foi o Decreto $\mathrm{n}^{0}$ 7247 de 19.04.1879, de Leôncio de Carvalho, que "Reforma o ensino primario e secundario no municipio da Côrte e o superior em todo o Imperio." (BRASIL, 1879) servindo de modelo para o restante do país, na medida em que, caso a escola funcionasse sob certos parâmetros receberia o reconhecimento oficial. Não nos dedicaremos aqui ao documento mais importante derivado desse Decreto que é o Parecer de Rui Barbosa. Porém, ele guarda e reforça todos os princípios liberais já proclamados nas leis anteriores: liberdade de ensino, porém sem a laicidade do Estado e consequentemente da escola pública e o incentivo e proteção à escola privada.

Uma primeira característica desse Decreto é a liberalidade no trato da educação: tudo é permitido ao cidadão, nada é obrigatório ao Estado. Ou seja, dentro dos parâmetros expostos nesse ordenamento legal o direito à educação continua com as mesmas características previstas na Constituição de 1824. Senão vejamos:

a) Já no artigo 2o o legislador declara que "os indivíduos de um e outro sexo, de 
7 a 14 annos de idade" têm a obrigação de frequentar a escola, porém ao invés de promover um outro direito do cidadão que é a possibilidade de chegar à escola, o mesmo legislador isenta os pais de enviar os meninos e meninas que morarem a mais de um quilômetro de distância da escola. Entre uma série de outras possibilidades de não-educação escolar, educação em outras escolas que não públicas, com séria isenção do Estado, exceto na fiscalização;

b) Não se preocupa com o cuidado pedagógico - o que significaria mais despesas - pois não prevê um atendimento àqueles alunos que por dificuldade não atingiram o mínimo necessário para os exames dentro do limite de 14 anos de idade, mas apenas lança-os à escola de adultos, provavelmente noturna, como recurso último para o seu aprendizado; é de se supor que milhares ficaram abandonados pelo caminho e, mesmo com condições financeiras propícias, esbarraram em descuidos pedagógicos que os tiraram do grupo de cidadãos;

c) Prevê atendimento ao aluno pobre, mas condiciona esse atendimento a receitas improváveis como multas - caso houvesse fiscalização suficiente -, donativos e verbas votadas pela Assembleia para este fim, não criando um programa permanente de assistência e acolhimento ao educando pobre. Ao final, ainda legisla sobre a gratuidade de matrículas a exames nos cursos superiores para os alunos pobres, mas em troca de uma excelência sem nenhum critério de medida;

d) O parágrafo $5^{\circ}$ do artigo $2^{\circ}$ é conclusivo quando inscreve na lei os excluídos do sistema escolar, dispensando do ensino por "inhabilidade physica ou moral e a indigência", não se obrigando a nenhum tipo de assistência efetiva e discriminatória que colocasse esse cidadão de segunda classe nas mesmas condições de um cidadão de primeira classe. Se considerarmos com Dubet (2004) que algumas "desigualdades são aceitáveis ou mesmo justas, quando não pioram as condições dos mais fracos" (DUBET, 2004, p. 546) uma lei que inscreve tal condição retira qualquer possibilidade de crescimento de uma nação retirando-lhes, à época, a oportunidade de aprender o mínimo: ler, escrever, contar. Quando tomamos por base o preceito constitucional de "decente subsistência" combinada com a expressão "indigência" percebe-se que na lei não há nenhuma preocupação da parte do Estado imperial brasileiro de promover a cidadania.

e) Respeito à liberdade religiosa, proporcionando condições para a frequência de alunos não católicos à escola, porém, na prática esse foi o artifício usado para permitir a abertura de escolas confessionais privadas, liberando o Estado de sua responsabilidade com uma escola laica e pública.

Em seu artigo $8^{\circ}$ a lei sinaliza com ações oficiais de que o governo "poderá" realizar. É a dubiedade da expressão que permite a um governo fazer qualquer coisa e afirmar que está cumprindo a lei. Assim, as escolas ou professores particulares gozam de livre trâmite no erário público justificados, convenientemente, pela lei.

O advento da República e a laicização da escola não resolveu o problema de uma 
educação para as massas, pois que o país continuava inserido no capitalismo mundial como uma matriz agrária detentora e receptora de mão de obra ainda não necessitada de melhor qualificação. A despeito de um discurso republicano moderno e contra uma mentalidade imperial e conservadora,

A Constituição de 1891 manteve um federalismo educacional quase nos mesmos termos do Ato Adicional e, ainda por cima, deixou a cargo da autonomia dos Estados declarar ou não a gratuidade (que não aparece na Constituição Federal de 1891) e a obrigatoriedade do ensino primário. (CURY, 2014, p. 27).

A tentativa de modernização das instituições, por meio de um golpe militar em 1889, reuniu liberais e positivistas que acreditavam na liberdade e na necessidade do ensino como ferramenta para a grandeza da nação. Porém, o país ainda era uma grande fazenda com seus senhores de engenho, coronéis da guarda nacional e barões do café. A pouca modernidade técnica trouxe pouca ou nenhuma modernidade político-institucional e

\begin{abstract}
Como por um toque da varinha mágica, o país agrário queria, de improviso, transformar-se numa potência industrial servida por largo setor terciário de comércio e Bancos, embora não dispusesse de know-how, nem de capitais suficientes. Multiplicavam-se as sociedades anônimas, companhias e iniciativas industriais. (BALEEIRO, 2012, p. 14).
\end{abstract}

Por isso, mais uma vez, não tivemos escola: não havia necessidade de alfabetização mesmo com a positividade mais liberal e econômica do termo. Não nos fazia falta. Alfredo Bosi (1992), em Dialética da Colonização, mostra-nos como nosso processo de modernização obedeceu ao modelo prussiano, ou seja, nossas elites sempre fizeram e fazem a revolução pelo alto, "antes que o povo a faça", e durante o Estado Novo a instrução pública vem atender aos novos anseios de um nascente capitalismo brasileiro. Ampliada, ela vai atender às classes urbanas qualificando-as para o trabalho na indústria, no comércio e na burocracia estatal. O setor de serviços provê sua própria qualificação, ainda nos moldes antigos de uma educação doméstica de pai para filho, de patrão para empregado. O Brasil se insere neste novo modelo de capitalismo educando os filhos dos trabalhadores para que se comportem como tal, adquirindo competências básicas para o manuseio de máquinas um pouco mais sofisticadas que aquelas de uma economia rural. E paramos por aí.

Inscritos na Constituição de 1891, os princípios liberais ainda não conseguem maior inserção no imaginário e nas leis que vão reger o país. Prendemo-nos ainda a uma cidadania restritiva onde a democracia é mera formalidade eleitoral. Mendigos e analfabetos não são alistáveis e, portanto, inelegíveis. O fato da menção a pessoas nessas duas condições de miserabilidade demonstra o fracasso de qualquer política educacional do Império, mas que, infelizmente, a República não vai se propor a resolver de imediato. Nem como direito do cidadão, nem como necessidade do empregador e muito menos como filantropia liberal.

$\mathrm{Na}$ concepção de cidadania e, portanto, de cuidado, aqueles que não sabem ler e escrever ocupam o mais baixo degrau na sociedade brasileira. Sobre a educação, a Constituição de 1891 é direta. Em seu "Artigo $72 \S 6^{\circ}$ - Será leigo o ensino ministrado nos estabelecimentos publicos" (BRASIL, 1891), não revogando e mantendo o que anteriormente já tinha sido definido pelo Decreto $\mathrm{n}^{\circ}$ 7, de 19 de novembro de 1889 que no 
seu Artigo $2^{\circ}$, $\S 2^{\circ}$ autoriza e determina aos Estados "Providenciar sobre a instrucção publica e estabelecimentos proprios a promovel-a em todos os seus gráos." (BRASIL, Decreto 7,1889 ). À exceção do caráter leigo do ensino público nada mais é acrescentado aos direitos dos cidadãos brasileiros relativos à educação na Constituição Federal de 1891. A Reforma Constitucional de 1926 não acrescenta absolutamente nada à Constituição.

Dessa forma, para concluirmos esta análise do atendimento do direito à educação no Império brasileiro cabe-nos lembrar de que a cordialidade brasileira transfere para o Estado a etiqueta doméstica daí dificultando qualquer tipo de acordo na medida em que acordos pressupõe o princípio da igualdade entre as partes dialogantes. Nossa cultura construiu durante o Império - e em vária medida se mantém - uma relação de força erigindo uma Constituição que ao privilegiar a instituição da Monarquia e do Estado abandonou a nação à sua própria sorte. Isso significou que não houve nos debates constituintes brasileiros, com as exceções e bastante ressalvas de 1946 e 1988, a situação de igualdade necessária para a disputa pelo Estado e como consequência a inscrição de direitos na Constituição.

O liberalismo brasileiro não se constitui num escopo de ideias que desemboca num partido político cujo principal mote deveria ser o Estado Mínimo, pois nossa cultura é de total dependência do Estado. A outra face da moeda é que não conseguimos constituir um partido político que conquiste o Estado para a nação. Durante o processo de Independência e constituição do Estado vimos grupos de interesses da elite disputando um lugar ao lado do Imperador. Aqueles que não viam no Imperador a razão para a instituição do Estado eram postos de lado, presos e isolados dos demais por colocar em risco uma elite que soube se comportar com a ciência de quem sabia que era apenas uma questão de ajustes e não de disputa. E esse ajuste final se dá com a Revolução Liberal em 1848. Daí em diante, até os dias de hoje, o liberalismo brasileiro se acomoda em várias espécies de partidos políticos resultando daí uma maior dificuldade das lutas populares, e entre elas a educação, pautarem a agenda do Congresso Nacional.

Em suma, não criamos, seja pela direita clássica ou pela esquerda revolucionária, partidos que sejam de fato partes da sociedade em disputa pelo Estado. Em que medida isso é resultado da nossa cultura uma vez que nossa cordialidade aceita a espera - 0 país do futuro - com manifestações de rua e quebradeiras sem se organizar política e partidariamente? Muito de nossas lutas pela educação não são o resultado das demandas do povo, mas do desejo e da certeza de intelectuais que acreditam na liberdade provocada pelo esclarecimento da razão pela via da educação.

A legislação educacional brasileira deixou e deixa o povo esperando. Esperamos que uma elite que se dizia liberal investisse na educação popular. Não aconteceu. A Reforma Liberal no final do Império também não fez da educação a sua prioridade. A promessa de popularização da educação na República só viu uma Lei de Diretrizes e Base na metade do século XX. Esperamos o bolo crescer e não vimos o direito à educação ser garantido e ampliado. Agora esperamos o petróleo do pré-sal. Até quando?

Logo no fim da Segunda Guerra Mundial, Samuel Becket (1906-1989), dramaturgo irlandês apresenta-nos Vladimir, seu personagem que logo no início da obra teatral "Esperando Godot" declara: "Vamos esperar até estarmos completamente seguros" (BECKET, 2005, p. 27). A expressão tanto vale para o passado quanto para o futuro. Mais 
tarde, ainda nessa longa espera seu amigo Estragon, ao ser interpelado sobre o que conversavam na tarde do dia anterior, responde "Ah... isto e aquilo... sobre as botas. (Com certeza). Isso, me lembrei, ontem à tarde ficamos falando das botas. A mesma conversa há cinquenta anos" (BECKET, 2005, p. 72, grifo do autor). Este é o dilema a que se propõe as pessoas na medida em que a cultura da espera torna-se o eterno ponto de partida para alguma coisa que ainda não se sabe onde vai chegar e que também não se planeja aonde se quer chegar. E passamos meses e anos conversando sobre botas sem nunca caminhar na direção do problema, esperando uma solução que, talvez, quem sabe um dia, virá do alto, das mãos ou da cabeça de um demiurgo. E assim passa-se uma geração onde a ação política se imediatiza num presente não planejado e não se planeja um futuro para as novas gerações. Godot é um incógnito, um desconhecido que nunca vem e dá pistas de que nunca virá, mas que enche os seus de esperança numa solução. É a espera das personagens que nos põem a pensar sobre o que fazer enquanto esperamos e que nos paralisa enquanto esperamos sem saber se até mesmo devemos esperar. Becket nos apresenta no pós-guerra uma humanidade embrutecida e cega à procura de uma razão que a ilumine e uma mão que a conduza tirando-a do buraco em que se meteu por não saber conduzir sua sorte (na obra, Lucky, uma personagem). Uma humanidade que não consegue aproveitar-se de sua fortuna. Becket nos põe de frente com a angústia de esperar por algo ou alguém sabido e desejado, porém eternamente adiado.

Geoffrey Canada é um educador estadunidense e abre, com seu depoimento, o filme "Esperando pelo Super-homem" de 2010 do cineasta Davis Guggenheim. Em seu depoimento ele explica o título que é também o enredo do filme: na sua infância ficara decepcionado quando sua mãe Ihe disse que o Super-homem, solução de todos os seus problemas, não existe. É um documentário, sequência de outro realizado dez anos antes, sobre a escola pública dos Estados Unidos neste início de século XXI. O documentarista apresenta pais cheios de esperança, crianças cheias de sonhos diante de uma realidade que põe a escola pública como objeto de desejo e sorte. A lógica imposta às crianças pelo sistema educacional é perversa na medida em que não prevê os cuidados necessários a elas. Em geral, o sistema educacional transmite-nos a sensação de que todos esperam pelo Super-homem como alguém que vai resolver o problema: do acesso e permanência, da qualidade, do financiamento. Assim aparecem, em ordem cronológica, vários presidentes da república - dos democratas Kennedy a Obama, passando pelos republicanos Ronald Reagan e Bush pai e filho - afirmando que resolveriam o problema da educação no país. Nos exames nacionais de 2009, o distrito de Colúmbia, onde fica a capital Washington D.C. atingiu a pior marca de todo o país: $12 \%$ de proficiência em língua inglesa para alunos de educação básica. Conclusão: o modelo de educação nos Estados Unidos, um país liberal desde sua fundação, também não vem dando certo. Está falido. Esta é a sentença no final do filme. Guggenheim transpira otimismo, mas tem certeza que não se pode continuar esperando. Porém, em sua chamada à luta para melhorar o sistema educacional isenta totalmente o Estado da sua responsabilidade sobre o assunto, acreditando que é a comunidade - essa ficção - o tão aguardado superhomem dos comuns mortais do país.

Sabemos, hoje no Brasil, como estamos em termos de Educação. Porém, continuamos a tagarelar e a esperar. Ou seja, fazemos do presente um aprendizado da 
espera, sem interrogar nosso passado para saber por que ficamos assim. Como Vladimir, estamos esperando para saber como ficamos, como se a espera, por si só, fosse esclarecedora. Nossos sistemas de avaliação educacional nos dizem. Sabemos onde estão os problemas do país, mas a nossa cordialidade política impede uma ação mais eficaz. Claro que a Democracia pressupõe a paciência necessária para conversarmos com o máximo de pessoas interessadas em determinado assunto, mas por outro lado é possível construir enquanto se prepara novos projetos. Afinal de contas, como esperamos nosso Godot? Quem é o nosso Super-homem?

Ainda não cremos na educação como um direito, apenas como uma necessidade. $E$ isso é uma característica de nossa cultura que devemos mudar.

\section{Referências}

ABREU, Marcelo de Paiva; LAGO, Luiz Aranha Correa do. A economia brasileira no Império: 1822-1889. Rio de Janeiro: PUC-RIO, s/d. Disponível em <www.econ.puc-rio.br>.

ALMEIDA, Paulo Roberto de. Teoria da jabuticaba I: prolegômenos. Revista Espaço Acadêmico, n. 54, ano V, nov. 2005. Disponível em: <http://www.espacoacademico.com.br/054/54almeida.htm>.

ANTUNES, Ricardo; ALVES, Giovanni. As mutações no mundo do trabalho na era da mundialização do capital. Educação e Sociedade, Campinas/SP, v. 25, n. 87, p. 335-351, maio/ago. 2004. Disponível em: <http://www.cedes.unicamp.br>.

ASSIS, Joaquim Maria Machado de. Teoria do medalhão. In: 50 contos de Machado de Assis. Seleção, introdução e notas de John Gledson. São Paulo: Companhia das Letras, 2007, p. 82-90.

BALEEIRO, Aliomar. 1891. 3 ed. Brasília: Senado Federal, Subsecretaria de Edições Técnicas, 2012. (Coleção Constituições Brasileiras, v. 2).

BECKETT, Samuel. Esperando Godot. Tradução de Fábio de Souza Andrade. São Paulo: Cosac Naify, 2005.

BOSI, Alfredo. Dialética da Colonização. São Paulo: Companhia das Letras, 1992.

BOBBIO, Norberto. Liberalismo e Democracia. Tradução de Marco Aurélio Nogueira. São Paulo: Brasiliense, 2000.

BRASIL. Constituição (1824). 3 ed. Brasília: Senado Federal, Subsecretaria de Edições Técnicas, 2012.

. Constituição (1891). 3 ed. Brasília: Senado Federal, Subsecretaria de Edições Técnicas, 2012.

. Decreto $\mathrm{n}^{\circ} 7$, de 19 de novembro de 1889. Dissolve e extingue as assembléas provinciaes e fixa provisoriamente as attribuições dos governadores dos Estados.

Disponível em: <http://www2.camara.leg.br/legin/fed/decret/1824-1899/decreto-7-20novembro-1889-517662-publicacaooriginal-1-pe.html>.

Decreto no 7247 de 19.04.1879 - Reforma o ensino primario e secundario no municipio da Côrte e o superior em todo o Imperio. Disponível em: <http://www2.camara.leg.br/legin/fed/decret/1824-1899/decreto-7247-19-abril-1879547933-publicacaooriginal-62862-pe.html>.

. Lei de 15 de dezembro de 1830. Orça a receita e fixa a despeza para o anno financeiro de 1831-1832. Disponível em:

<http://www2.camara.leg.br/legin/fed/lei_sn/1824-1899/lei-38056-15-dezembro-1830- 
565833-publicacaooriginal-89571-pl.html>.

. Lei de 15 de outubro de 1827. Manda crear escolas de primeiras letras em todas as cidades, villas e logares mais populosos do Imperio. Disponível em: <http://www.planalto.gov.br/ccivil_03/Leis/LIM/LIM-15-10-1827.htm>.

CARVALHO, Marcus Vinícius Corrêa. Moderno, modernidade, modernização: polissemias e pregnâncias. In: GIL, Natália; ZICA, Matheus da Cruz e; FARIA FILHO, Luciano Mendes de (Orgs.). Moderno, modernidade e modernização: a educação nos projetos de Brasil séculos XIX e XX. Belo Horizonte: Mazza Edições, 2012, v. 1, p. 13-34.

CURY, Carlos Roberto Jamil. Educação e direito à educação no Brasil: Um histórico pelas Constituições. Belo Horizonte: Mazza Edições, 2014.

DUBET, François. O que é uma escola justa? Cadernos de Pesquisa, São Paulo, v. 34, n. 123, p. 539-555, set./dez. 2004. Disponível em:

<http://www.scielo.br/pdf/cp/v34n123/a02v34123.pdf>.

GIDDENS, Anthony. As consequências da modernidade. Tradução de Raul Fiker. São Paulo: Editora UNESP, 1991. (Biblioteca básica).

GUGGENHEIM, Davis. Esperando pelo Super-homem. Documentário, 111 min., 2010. Disponível em: <https://vimeo.com/67325868>.

MATTOS, Ilmar Rohloff de; GONÇALVES, Márcia de Almeida. O império da boa sociedade: a consolidação do Estado imperial brasileiro. São Paulo: Atual, 1991. (Coleção História em documentos).

NOGUEIRA, Octaciano. 1824. 3 ed. Brasília: Senado Federal, Subsecretaria de Edições Técnicas, 2012. (Coleção Constituições Brasileiras, v. 1).

POCHMANN, Márcio. Proteção social na periferia do capitalismo: considerações sobre o Brasil. São Paulo em Perspectiva, São Paulo, v. 18, n. 2, p. 3-16, abr./jun. 2004.

Disponível em: <http://www. scielo.br/pdf/spp/v18n2/a02v18n2.pdf>.

SILVA, José Bonifácio de Andrada e. Projetos para o Brasil. São Paulo: Cia das Letras; Publifolha, 2000. (Coleção Grandes nomes do pensamento brasileiro).

DALVIT GREINER DE PAULA é Doutorando em Educação na UFMG e Mestre em Educação pela UEMG. Especialista em Docência do Ensino Superior pela Esab e em Gestão Cultural pela Pucminas.

Endereço: Rua Geraldo Ferreira de Abreu, 25 - Floramar - 31.742-330 - Belo Horizonte/MG

- Brasil.

E-mail: dalvit.greiner@gmail.com

VERA LÚCIA NOGUEIRA é Doutora em Educação pela Universidade Federal de Minas Gerais - UFMG - e coordenadora do PPG em Educação e Formação Humana da FaE/UEMG - Universidade do Estado de Minas Gerais.

Endereço: Rua Professor Hermínio Guerra - 31710-040 - Belo Horizonte/MG - Brasil.

E-mail: vlnogueira2010@gmail.com

Recebido em 19 de julho de 2015.

Aceito em 15 de novembro de 2015. 